\title{
Longitudinal Growth in Height, Weight, and Bone Age of Guatemalan Ladino and Indian Schoolchildren
}

\author{
BARRY BOGIN 1 , TIMOTHY SULLIVAN ${ }^{2}$, ROLAND HAUSPIE ${ }^{3}$, AND \\ ROBERT B. MACVEAN ${ }^{4}$ \\ 1 Department of Behavioral Sciences, University of Michigan, Dearborn, \\ Michigan 48128; ${ }^{2}$ Center for Human Growth, University of Michigan, Ann \\ Arbor, Michigan 48109; ${ }^{3}$ Lab Anthropogentika, Free University of \\ Brussels, 1050 Brussel, Belgium; ${ }^{4}$ Universidad del Valle de Guatemala, \\ A.P. No. 82, Guatemala City, Guatemala
}

\begin{abstract}
Three longitudinal samples of Guatemalan schoolchildren are compared for amounts and rates of growth in height, weight, and bone age. The samples include children of two ethnic backgrounds: Ladinos, Spanish-speaking people of, generally, Western cultural orientation; and Indians, people of Mayan cultural descent. The Indians are of very low socioeconomic status (SES) and attend a public school in a rural village. The Ladinos come from two SES groups living in Guatemala City, one of high SES attending a private school and the other of low SES attending a public school. Graphical and statistical analyses show that for all samples of boys and girls there are, generally, significant differences between samples (high SES > low SES > Indian) for amounts of growth in height, weight, and bone age. Boys show significant differences in rates of growth between samples, with the high SES sample growing more rapidly than the two low SES samples. Girls show significant differences in the rate of growth in height, but not in the rate of growth in weight or bone age. For both boys and girls, rates of growth in height and weight differ more between samples than does rate of skeletal development. These results demonstrate that 1) SES-related deficits in growth are cumulative during childhood and early adolescence, that 2) rates of growth for boys are, generally, more sensitive to the influence of SES than are the growth rates of girls, and that 3) childhood growth deficits of low SES children are likely to carry over into adulthood.
\end{abstract}

Children and adolescents may be measured on a single occasion to assess the status of their size and maturity, but repeated measurements of the same individual are necessary if the goal is to characterize features of the dynamic aspects of growth and development. Longitudinal data are preferred when the patterns of growth of two or more populations of children are compared. Only a longitudinal analysis allows for a determination of the rates of growth and the timing of developmental events that result in differences in size and maturity.

In this paper, a longitudinal approach is taken to characterize growth in height and weight and the development of bones of the hand and wrist of children from three populations living in Guatemala. The populations differ in socioeconomic status (SES) and ethnicity: One is of low SES Mayan Indian children; the second is of low SES Ladino children (non-Indian Guatemalans); and the third is of high SES Ladino children. Few sets of longitudinal data exist for the growth and development of children from the lower SES classes of Latin America, especially children of Indian ethnicity. Thus, the data presented in this paper contribute toward a cross-cultural understanding of human physical development, and, more specifically, the conclusions examine the consequences of low SES on rates of change in size and skeletal maturity during childhood and adolescence.

Received May 26, 1988; accepted October 22, 1988. 


\section{MATERIALS AND METHODS}

The subjects for this report are participants in the Longitudinal Study of Child Development conducted by the Universidad del Valle de Guatemala. This ongoing study was designed to characterize the growth and development of children attending schools in and near Guatemala City (see Bogin and MacVean, 1983, 1984, for general background). Once each year, children attending schools participating in the study are measured for a variety of physical and cognitive characteristics. This sampling procedure results in a mixed-longitudinal research design. The advantage of such a design over a pure longitudinal design is that it maximizes the amount of data available for study and still provides reasonable estimates of means and variances for both amounts of growth and rates of growth. Moreover, the mixed-longitudinal design avoids two problems of pure longitudinal or pure cross-sectional analyses: Longitudinal data may confound effects due to growth with effects due to time-of-measurement (season, individual circumstances, etc.), and cross-sectional data may confound effects due to growth with effects due to cohort, e.g., year of birth effects (van't Hoff et al., 1977).

From the data on file, longitudinal sets of measurements were selected for three samples. These samples are 1) Ladino children of high SES attending a private school in Guatemala City, 2) Ladino children of low SES attending a public school in Guatemala City, and 3) Indian children of low SES attending a public school in a village near Guatemala City. Ladinos are of mixed Spanish and Mayan Indian ethnic descent, speak Spanish, dress in "western-style" clothing, and have western-oriented cultural values. Indians are the cultural descendants of the pre-Columbian Maya. The Indian sample of this study belongs to the Cakchiquel-speaking language group of Guatemala. The Cakchiquel Indians have distinctive clothing and a nonwestern set of cultural values (Pettersen, 1976).

SES is determined by a composite score for parental education and occupation. The score has a range of 4 to 15 points. The mean values of SES are high SES Ladinos $=12.21$ \pm 3.39 , low SES Ladinos $=5.75 \pm 0.40$, low SES Indians $=4.96 \pm 0.57$. The mean difference between the high SES Ladinos and the other two low SES groups is statistically significant at $P=.01$. The statistical difference between the low SES Ladinos and Indians has a value of $P=.10$, which may be interpreted as "borderline" significance. Site visits to the schools and the analysis of SES scores indicate that each school is relatively homogeneous with respect to SES. Briefly, the parents of the high SES Ladino children are, mostly, professionals or owners of business and industries. The parents of the low SES Ladinos are skilled and semiskilled laborers often earning only the official minimum wage (about $\$ 3.00$ U.S. per day). The parents of the very low SES Indian children are employed, predominately, as tailors or seamstresses for clothing manufactures or as self-employed street vendors of textiles and agricultural produce. The parents producing clothing are paid "piecework" wages, e.g., about $\$ 0.25$ (in U.S. dollars) for a finished shirt or blouse.

Because of the homogeneity of economic and sociocultural characteristics within school groups, it is most parsimonious to analyze the growth and development of these children by school of attendance. Accordingly, school group, a proxy measure for SES, is the unit of analysis in this paper.

Children were selected if they were examined on at least four occasions. For the high SES and low SES Ladino samples examinations may have occurred between the years 1976 and 1985, inclusive. For the Indian sample the measurements were taken between 1979, the year this school was added to the longitudinal study, and 1985. From 1976 to 1980 children in all grades (1-6) were measured once a year at equidistant inter vals (e.g., every March 1st-10th). Since 1980, children in each school are examined once a year only in grades $1,2,4$, and 6 . Thus a child completing elementary school without repeating a grade would be measured only four times, with an interval between exami. nations of 1 year for grades 1 and 2 and 2 years for grades 4 and 6 . Some children, however, repeat grades (especially in the low SES Ladino and Indian schools) and have 3 or more years of annual measure ments. To calculate rates of growth that are comparable for all children, the difference between consecutive measurements of each individual child was computed by subtraction and this difference was divided by the number of annual intervals between observations.

For the analysis of amounts of growth 
children were grouped into whole-year age cohorts (e.g., 6.00-6.99 years old) with mean ages at approximately the midpoint of the range (e.g., 6.50). For the analysis of rates of growth children were grouped into half-year age cohorts, e.g., 5.00-5.49, 5.50-5.99, .. 13.50-13.99, based on the date of birth of each child. The mean age of each cohort is, approximately, the midpoint of the range; the 5.00-5.49-year-old group averages 5.25 years of age. Half-year growth rates are more sensitive to short-term variation in growth, especially at adolescence, than are yearly increments.

The mixed longitudinal design resulted in the following number of individual children: 86 boys and 100 girls from the high SES Ladino school; 181 boys and 132 girls from the low SES Ladino school; and 171 boys and 90 girls from the low SES Indian school. The number of children by age and sex for the mixed-longitudinal sample is given in Table 1. The children were born in different years, and the distribution of children for each school group and sex is presented by age and year of birth in Figure 1. Although the range in age is 5 to 17 years, for statistical analysis in this paper the age range is truncated to 6.00 to 13.99 years. There are too few children outside this range, especially in the low SES samples, to permit unbiased evaluation.

In the present report, data for height, weight, and bone age are analyzed. Proce-

TABLE 1. Numbers of children by age and sex for the mixed-longitudinal samples from each school group 1

\begin{tabular}{|c|c|c|c|c|c|c|}
\hline \multirow[b]{3}{*}{ Age } & \multicolumn{6}{|c|}{ School group } \\
\hline & \multicolumn{2}{|c|}{$\begin{array}{c}\text { High SES } \\
\text { Ladino }\end{array}$} & \multicolumn{2}{|c|}{$\begin{array}{l}\text { Low SES } \\
\text { Ladino }\end{array}$} & \multicolumn{2}{|c|}{$\begin{array}{l}\text { Low SES } \\
\text { Indian }\end{array}$} \\
\hline & Boys & Girls & Boys & Girls & Boys & Girls \\
\hline 5 & 77 & 81 & - & - & 17 & 4 \\
\hline 6 & 79 & 85 & 42 & 24 & 24 & 4 \\
\hline 7 & 77 & 90 & 136 & 86 & 111 & 55 \\
\hline 8 & 82 & 92 & 132 & 101 & 139 & 73 \\
\hline 9 & 84 & 97 & 77 & 65 & 115 & 68 \\
\hline 10 & 83 & 98 & 102 & 75 & 93 & 56 \\
\hline 11 & 85 & 97 & 76 & 56 & 83 & 49 \\
\hline 12 & 84 & 101 & 60 & 47 & 75 & 43 \\
\hline 13 & 77 & 88 & 27 & 32 & 43 & 27 \\
\hline 14 & 46 & 40 & 12 & 9 & 19 & 5 \\
\hline 15 & 37 & 41 & - & - & 8 & - \\
\hline 16 & 13 & 19 & - & - & - & - \\
\hline 17 & 19 & 17 & - & - & - & - \\
\hline
\end{tabular}

${ }^{1}$ This is a cross-sectional presentation of the mixed-longitudinal sample. The total number of individual children from each group is as follows: high SES Ladinos-boys $=86$, girls $=100$; low SES ladinos-boys $=181$, girls $=132$; low SES Indians-boys $=171$, girls $=90$ dures of measurement for height and weight were reported previously (Johnston et al., 1973; Bogin and MacVean, 1978, 1984). Bone age was assessed by using the methods of Greulich and Pyle (1959). A description of the radiographic methods was described by Bogin and MacVean (1983). It is fortunate
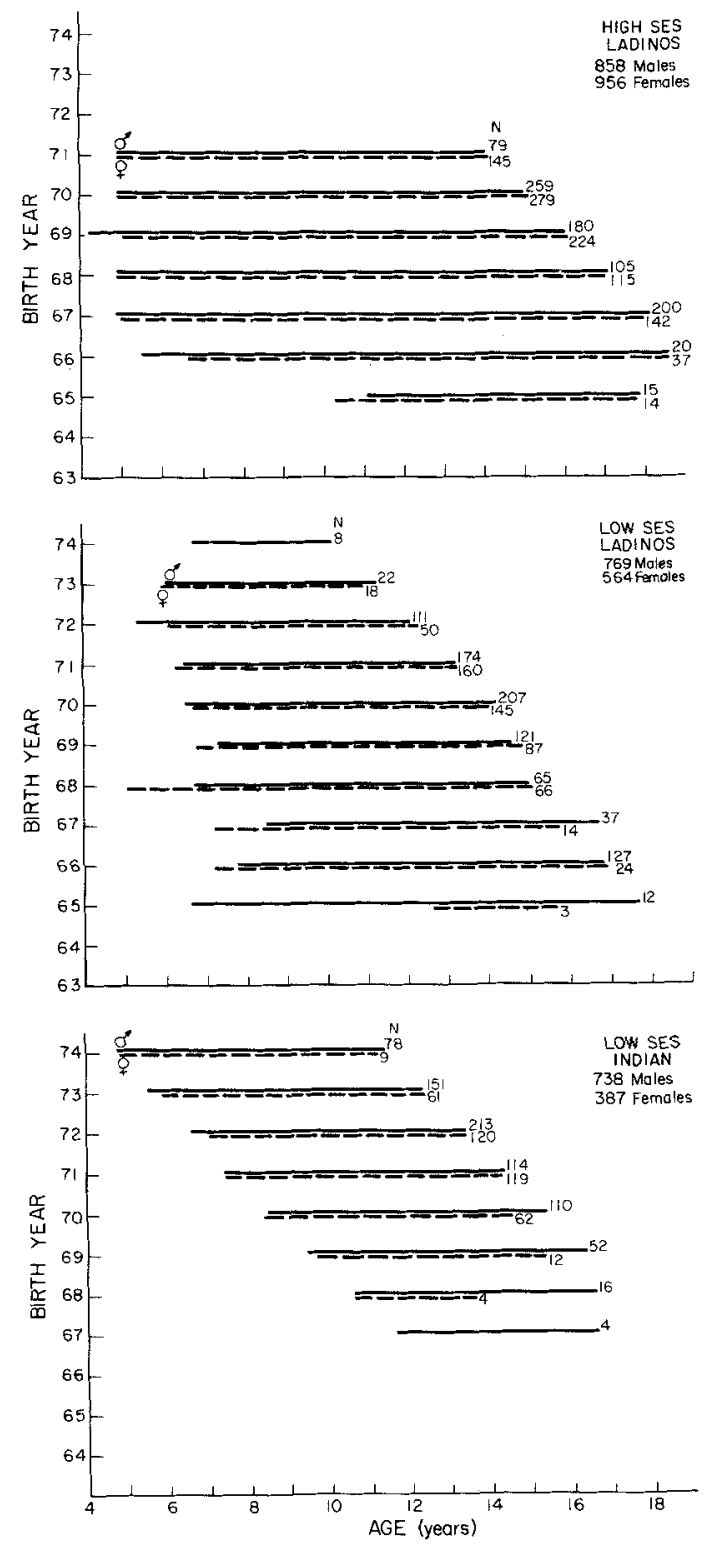

Fig. 1. Sample sizes by sex, age, and year of birth for the three samples of Guatemalan schoolchildren. 
that during the period 1976 to 1985 the personnel responsible for the growth measurements changed little: In fact two people have been part of this team (of five) for the entire time. Further, only two individuals were responsible for taking hand-wrist radiographs and estimating bone ages. Accuracy and reliability are checked periodically, most recently in August 1987. Intra-observer reliabilities are .90 or higher for all measurements. Interobserver reliabilities for height and weight average .74 . The reliability between the two observers estimating bone age is .87. The differences between all observers are small and randomly distributed, so that there are no significant biases in the recording of the data.

The amounts and rates of growth for the three samples of boys and girls are analyzed in two ways. First graphically, by plotting the mean values for height, weight, and bone age at each chronological age and by plotting the mean rates in growth and development at each 6-month age interval. Secondly, an analysis of covariance (ANCOVA) is used to test for differences in the mean amount of growth and differences in the rate of growth between children in each school. ANCOVA methods described by Brownlee (1965) were used and the analysis was performed with the MIDAS (Fox and Guire, 1976) package of statistical programs.

The model for the ANCOVA is:

$$
\begin{gathered}
\text { Measurement }=\text { Age }+ \text { School }+ \\
(\text { Age } \times \text { School })-\text { error }
\end{gathered}
$$

where Measurement is height, weight, or bone age. Age is the covariate, and School is a categorical variable that identifies children according to the school they attend. The value of this model over simple analysis of variance is that ANCOVA eliminates the problem of high correlations between the consecutive measurements for each child. The ANCOVA produces mean values for each measurement, adjusted for age, by least-squares regression. This technique assumes data that are normally distributed and homoscedastic. No serious deviations from normality were noted in this data set. Graphic plots (i.e., scatter diagrams) of each measurement against age showed that the data are homoscedastic in distribution. The coefficients (i.e., slopes) of the regression lines may be tested for equality, i.e., for differences between schools in rate of growth. The interaction term in the ANCOVA model tests for equality between schools in growth rates.

\section{RESULTS}

In Figures 2-4 the mean values for height, weight, and bone age by chronological age, and the semiannual mean rates for each measure, are given for the three samples of boys. Similar information for the three samples of girls is given in Figures 5-7. The graphs for high SES Ladino sample include more data points because sufficient sample sizes were available at ages 14 and above. In general, the data for both amounts of growth and rates of growth and development are
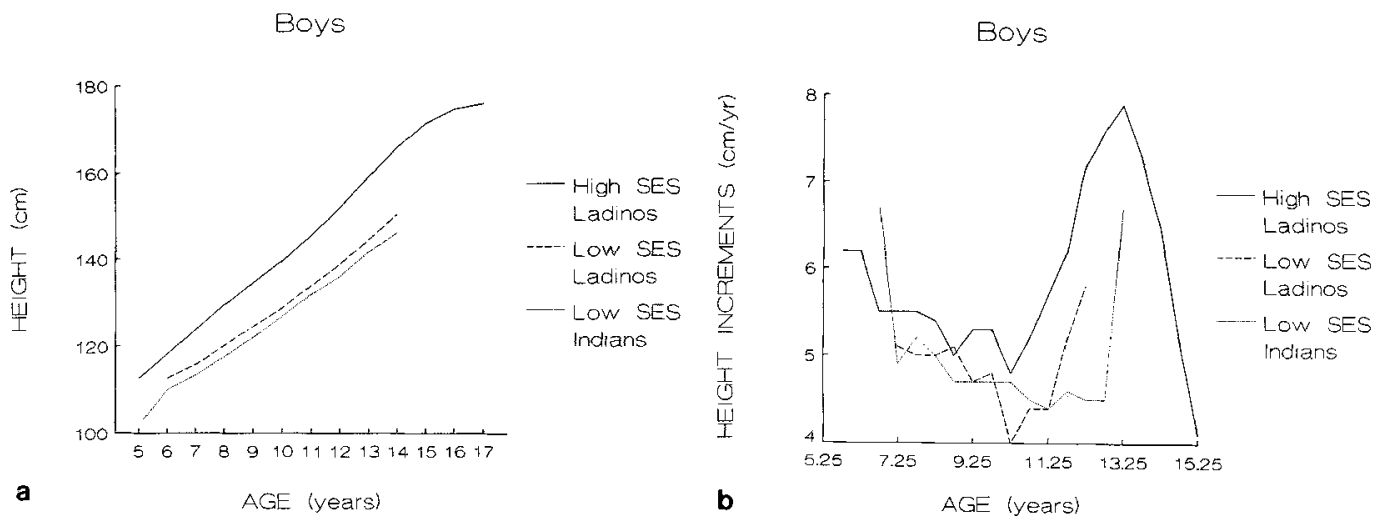

Fig. 2. Curves for amount and rate of height growth by age for the three samples of boys. 

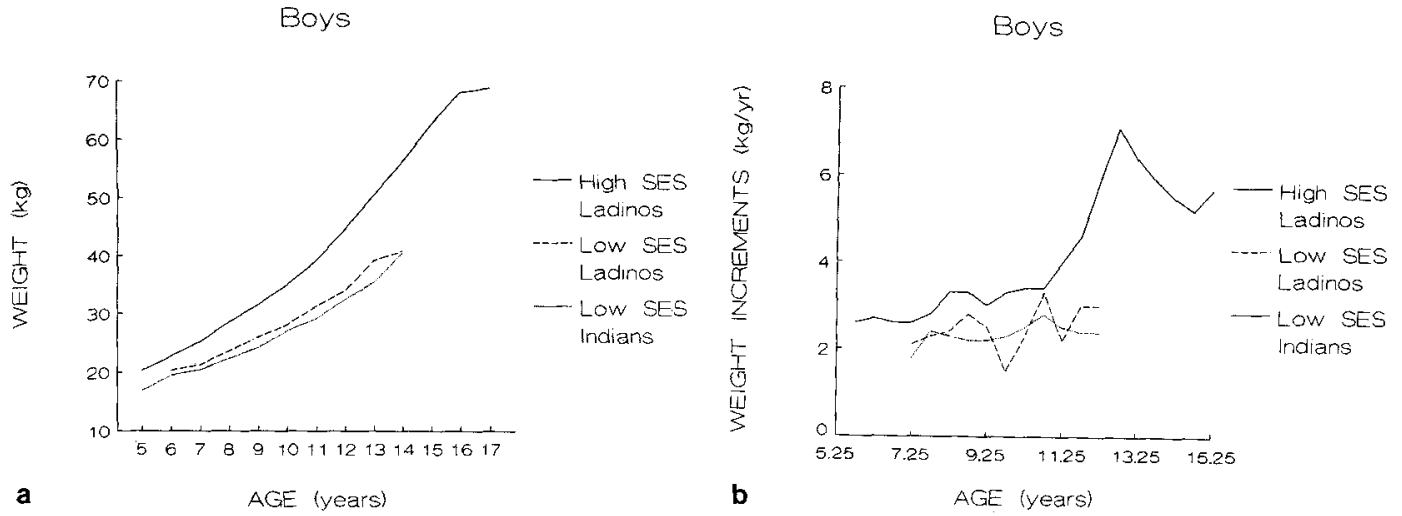

Fig. 3. Curves for amount and rate of weight growth by age for the three samples of boys.

ordered as follows: High SES Ladinos > low SES Ladinos > low SES Indians.

The graphs for rates of growth show that high SES Ladino boys have a well-defined adolescent growth spurt in height and weight. Data for the lower SES groups are not complete for the adolescent years; however, the graphs of growth rate indicate that the low SES Ladino and Indian boys have a later onset of the adolescent growth spurt. From these graphs the chronological age at "takeoff" for the spurt may be estimated at about 10 years for the high SES boys, 11 years for the low SES Ladino boys, and 13 years for the low SES Indian boys. The rates of growth in height for the girls do not show marked differences in the timing of the adolescent spurt; all the groups appear to reach "takeoff" between the ages of 9 and 10 years. Note that the low SES Indian girls' height increments are almost always about 0.5 $\mathrm{cm} /$ year less than the rate for the other two groups. The pattern of increments in weight is less clear, but it seems that take-off begins by about age 10 years for all three groups.

In theory, bone age increments should increase at the rate of 1 year for each 1 -year increase in chronological age (Greulich and Pyle, 1959). This means that the graphs of bone age against chronological age should produce straight lines at a $45^{\circ}$ angle with respect to the $x$ and $y$ axes. The graphs of the bone age increments for the boys (Fig. 4) and the girls (Fig. 7) show that the theoretical expectation does not conform to observations across the chronological age range.
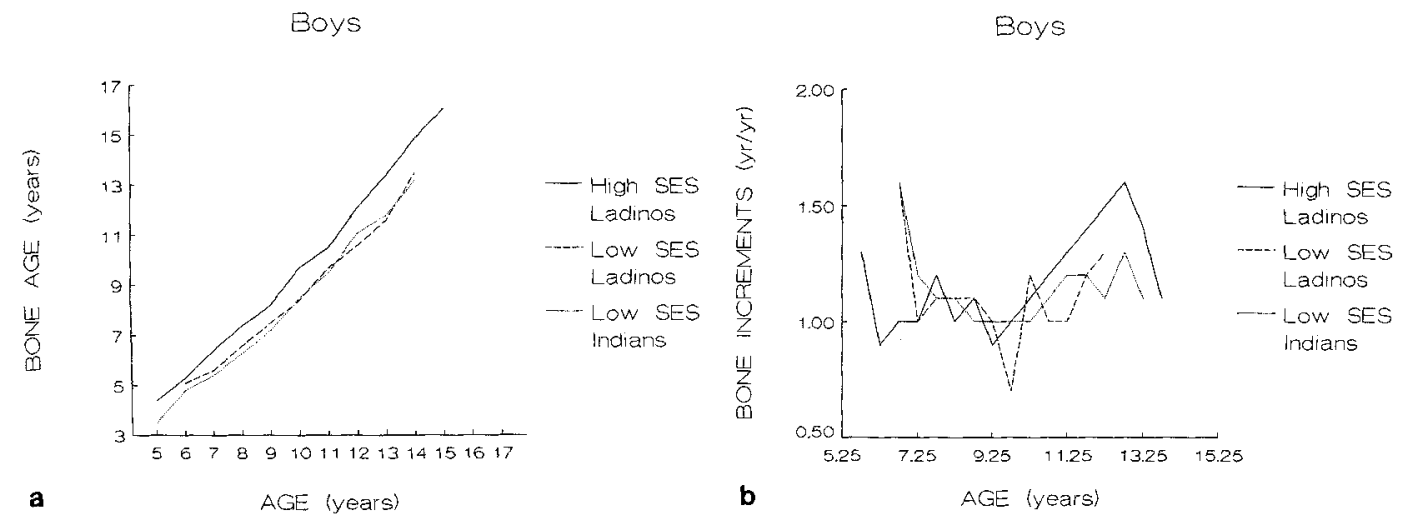

Fig. 4. Curves for amount and rate of bone age development for the three samples of boys. 
Girls

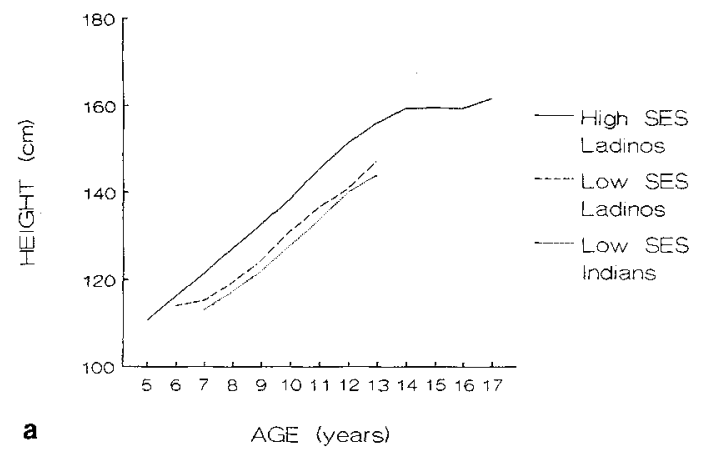

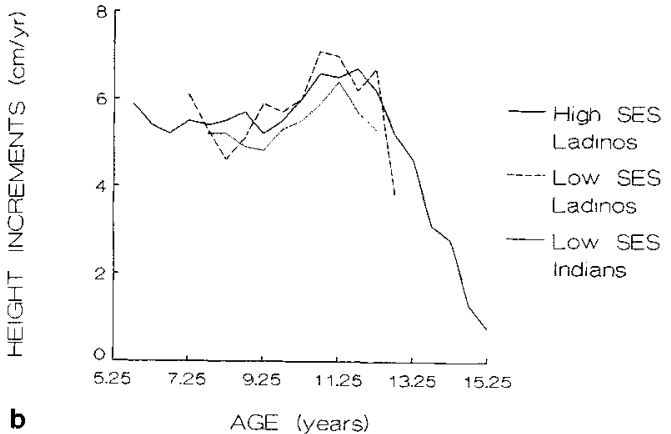

Fig. 5. Curves for amount and rate of height growth by age for the three samples of girls.

Overall, there appears to be a general trend for increases in bone age over time, especially for the three groups of girls. Perhaps the trend is due to an overrepresentation of early maturing children in the older chronological age groups, but as we lack population-specific bone development data for Guatemalan children the cause of the trend is not certain.

The statistical significance of differences in the patterns of growth for each school group was assessed with the ANCOVA. The results are presented in Tables 2-4 for the boys and Tables 5-7 for the girls. The tables are divided into three parts. The top part reports the sample size, the raw mean (for ages 6.00-13.99), and the age-adjusted mean for measurements within each school group. Next the constant term and the coefficient of the regression are given, followed by statistical tests of the "goodness-of-fit" of

Girls

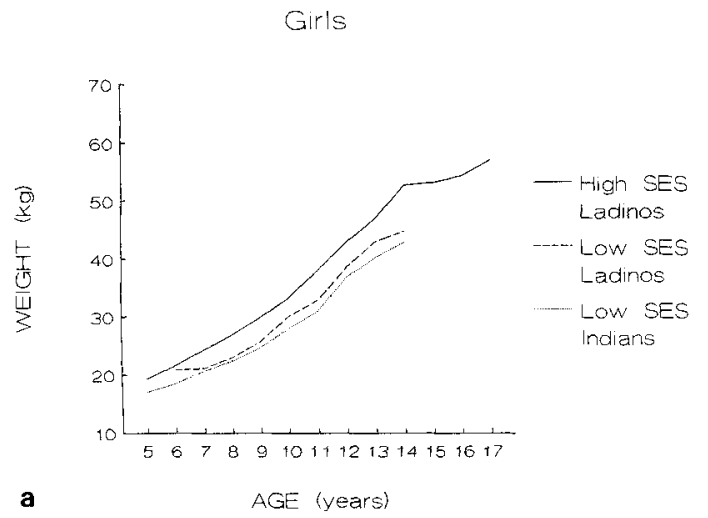

a the linear regression to the raw data. The middle part of the tables includes two tests for differences in growth between the three school groups. The first, labeled "Deviation of group means," tests for differences between the three school groups in amount of growth. The second, labeled "Equality of slopes," tests for differences between the three school groups in rates of growth. If these tests of difference in amount or rate of growth are significant, then the difference between pairs of school groups may be tested. The bottom part of the tables includes these post hoc pairwise comparisons, which were analyzed by the Scheffe method. Statistical significance was accepted at $P=.05$; NS indicates that a test was not significant. NA indicates that a text was not applicable.

The ANCOVA technique produced significant adjustments in the raw mean values for each measurement variable in all schools

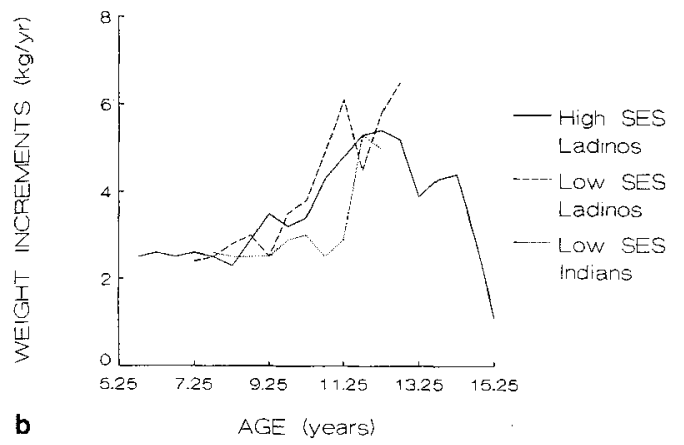

Fig. 6. Curves for amount and rate of weight growth by age for the three samples of girls. 

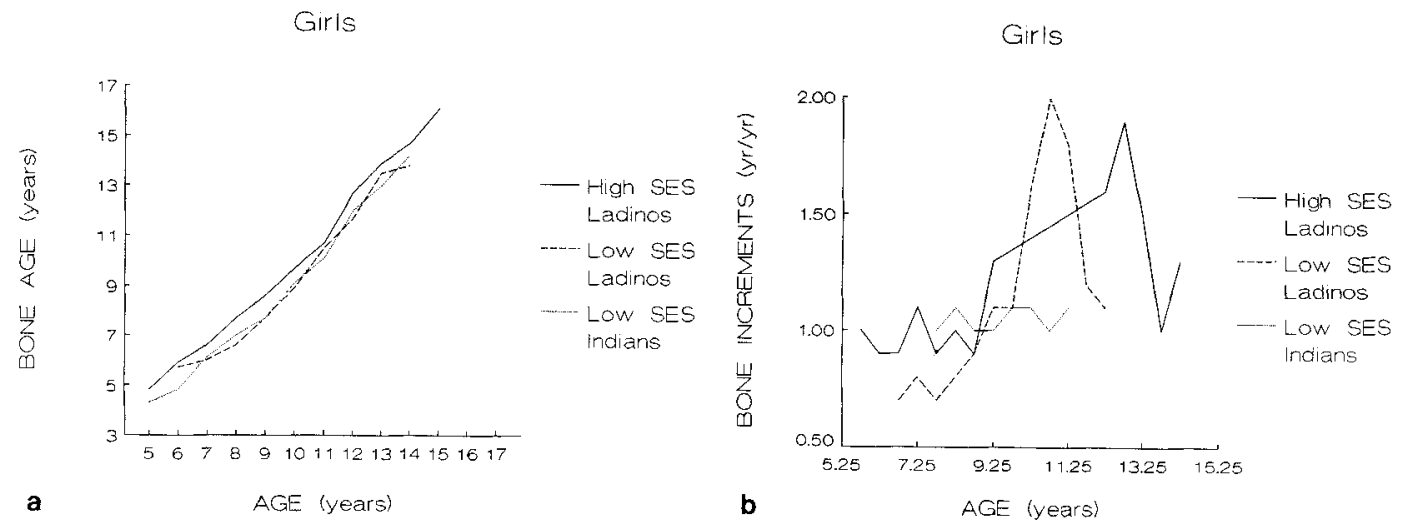

Fig. 7. Curves for amount and rate of bone age development for the three samples of girls.

and both sexes. The relatively small standard errors (SE) of regression and the, generally, high $\mathrm{R}^{2}$ values indicate that ANCOVA was an appropriate method of analysis. That is, within the age range 6 to 13 years, the data may be analyzed with linear statistical methods.

TABLE 2. Analysis of covariance for the height measurements of boys from each school

\begin{tabular}{|c|c|c|c|}
\hline & \multicolumn{3}{|c|}{ School samples } \\
\hline & High SES & Low SES & Indian \\
\hline Sample size & 651 & 652 & 683 \\
\hline Mean & 135.2 & 126.2 & 123.4 \\
\hline $\begin{array}{l}\text { Adjusted mean } \\
\text { (SE) }\end{array}$ & $\begin{array}{r}135.9 \\
(.23)\end{array}$ & $\begin{array}{c}125.8 \\
(.23)\end{array}$ & $\begin{array}{l}123.1 \\
(.24)\end{array}$ \\
\hline Constant & 83.9 & 83.7 & 80.3 \\
\hline Coefficient & 5.8 & 4.6 & 4.7 \\
\hline $\begin{array}{l}\text { SE of } \\
\text { regression }\end{array}$ & 6.2 & 6.6 & 5.7 \\
\hline $\mathrm{R}^{2}$ & 0.85 & 0.67 & 0.73 \\
\hline $\begin{array}{l}\text { Significance of } \\
\text { regression }\end{array}$ & 0.01 & $<0.01$ & $<0.01$ \\
\hline \multicolumn{4}{|c|}{ Tests of regressions } \\
\hline & $\begin{array}{c}\text { Mean } \\
\text { square }\end{array}$ & F & $P$ \\
\hline $\begin{array}{l}\text { Deviation of } \\
\text { group means }\end{array}$ & $6,472.1$ & 170.2 & $<.01$ \\
\hline $\begin{array}{l}\text { Equality of } \\
\text { slopes }\end{array}$ & $1,441.3$ & 37.9 & $<.01$ \\
\hline Error & 38.0 & & \\
\hline \multicolumn{4}{|c|}{ Pairwise comparisons of regression results } \\
\hline Contrast & & $\begin{array}{l}P \text { for } \\
\text { means }\end{array}$ & $\begin{array}{c}P \text { for } \\
\text { slopes }\end{array}$ \\
\hline High SES-low & ES & $<.01$ & $<.01$ \\
\hline High SES-Ind & & $<.01$ & $<.01$ \\
\hline Low SES-Ind & & $<.01$ & NS \\
\hline
\end{tabular}

The "Tests of regressions" section indicates that significant differences exist between the three groups of boys (Tables 2-4) in both amount of growth and rate of growth in height, weight, and bone age. The "Pairwise comparisons" for amount of growth (" $P$ for means") indicate that high SES Ladino boys are, on average, significantly taller, heavier, and more mature skeletally than both groups of low SES boys. Low SES Ladinos are significantly taller and heavier than low SES Indian boys. The low SES Ladino and Indian boys are not significantly different in bone age.

The pairwise comparisons for rate of growth (" $P$ for slopes") show that high SES Ladino boys grow at a faster rate in both height and weight than do the low SES groups of boys. Low SES Ladino boys grow at a significantly faster rate in weight, but not in height, than the low SES Indian boys. The rate of skeletal maturation of high SES Ladino boys is significantly faster than in low SES Ladino boys but is statistically equal to that for low SES Indian boys. The skeletal maturation of Indian boys is significantly faster than that for low SES Ladino boys. This is the only case in which the value of a growth variable for the Indian children exceeds the average value for low SES Ladino children. Note that the size of the $F$ statistics for amount and rate of growth for bone age (Table 4, middle section) are relatively small compared with the F statistics for height (Table 2) and weight (Table 3). This may indicate that membership in a particular school group, i.e., gen- 
TABLE 3. Analysis of covariance for the weight measurements of boys from each school

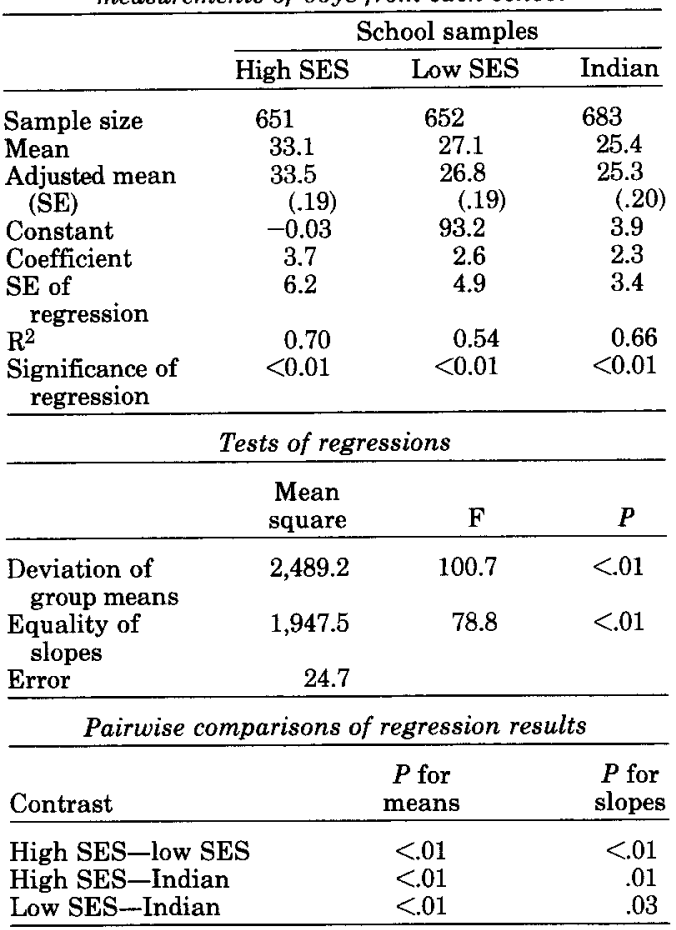

TABLE 4. Analysis of covariance for the bone age measurements of boys from each school

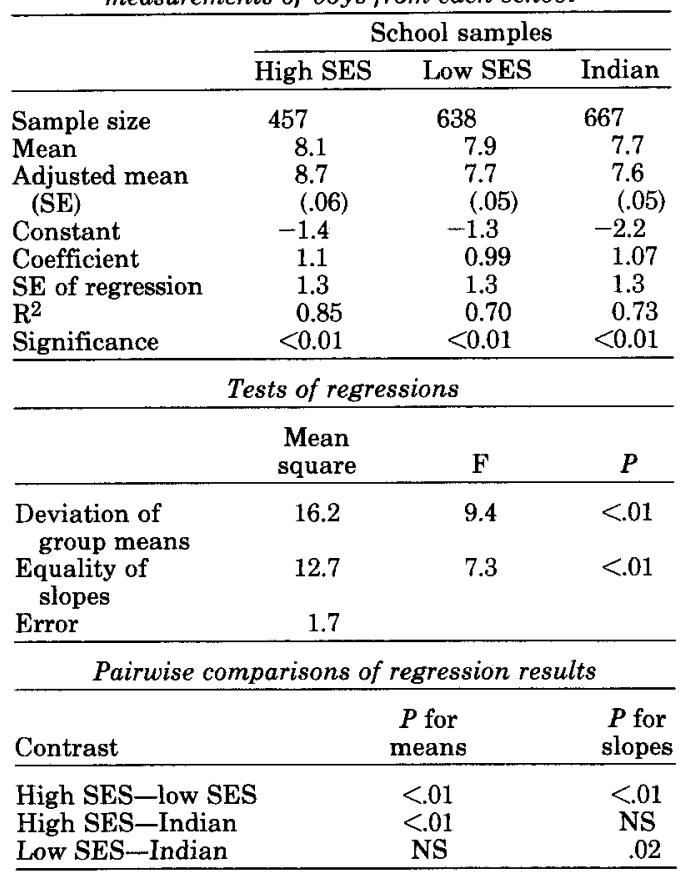

TABLE 5. Analysis of covariance for the height measurements of girls from each school

\begin{tabular}{|c|c|c|c|}
\hline & \multicolumn{3}{|c|}{ School samples } \\
\hline & High SES & Low SES & Indian \\
\hline Sample size & 748 & 486 & 375 \\
\hline Mean & 133.9 & 127.8 & 125.4 \\
\hline $\begin{array}{l}\text { Adjusted mean } \\
\text { (SE) }\end{array}$ & $\begin{array}{l}134.8 \\
(.21)\end{array}$ & $\begin{array}{l}127.1 \\
(.27)\end{array}$ & $\begin{array}{ll}124.4 \\
(.32)\end{array}$ \\
\hline Constant & 81.5 & 79.6 & 75.1 \\
\hline Coefficient & 5.7 & 5.1 & 5.3 \\
\hline $\mathrm{SE}$ of regression & 6.4 & 6.1 & 5.4 \\
\hline $\mathrm{R}^{2}$ & 0.83 & 0.75 & 0.78 \\
\hline $\begin{array}{l}\text { Significance of } \\
\text { regression }\end{array}$ & $<0.01$ & $<0.01$ & $<0.01$ \\
\hline \multicolumn{4}{|c|}{ Tests of regressions } \\
\hline & $\begin{array}{l}\text { Mean } \\
\text { square }\end{array}$ & F & $P$ \\
\hline $\begin{array}{l}\text { Deviation of } \\
\text { group means }\end{array}$ & 450.3 & 12.0 & $<.01$ \\
\hline $\begin{array}{l}\text { Equality of } \\
\text { slopes }\end{array}$ & 340.1 & 9.1 & $<.01$ \\
\hline Error & 37.5 & & \\
\hline \multicolumn{4}{|c|}{ Pairwise comparisons of regression results } \\
\hline Contrast & & $\begin{array}{l}P \text { for } \\
\text { means }\end{array}$ & $\begin{array}{l}P \text { for } \\
\text { slopes }\end{array}$ \\
\hline High SES-low & & $<.01$ & $<.01$ \\
\hline High SES-Indi & & $<.01$ & $<.01$ \\
\hline Low SES-India & & $<.01$ & NS \\
\hline
\end{tabular}

TABLE 6. Analysis of covariance for the weight measurements of girls from each school

\begin{tabular}{|c|c|c|c|}
\hline & \multicolumn{3}{|c|}{ School samples } \\
\hline & High SES & Low SES & Indian \\
\hline Sample size & 748 & 486 & 375 \\
\hline Mean & 31.8 & 28.8 & 27.3 \\
\hline $\begin{array}{l}\text { Adjusted mean } \\
\text { (SE) }\end{array}$ & $\begin{array}{l}32.4 \\
\quad(.19)\end{array}$ & $\begin{array}{l}28.3 \\
(.24)\end{array}$ & $\begin{array}{c}26.7 \\
(.29)\end{array}$ \\
\hline Constant & 0.02 & -3.0 & -3.0 \\
\hline Coefficient & 3.5 & 3.4 & 3.2 \\
\hline SE of regression & 6.2 & 5.4 & 4.1 \\
\hline $\mathrm{R}^{2}$ & 0.67 & 0.62 & 0.69 \\
\hline $\begin{array}{l}\text { Significance of } \\
\text { regression }\end{array}$ & $<0.01$ & $<0.01$ & $<0.01$ \\
\hline \multicolumn{4}{|c|}{ Tests of regressions } \\
\hline & $\begin{array}{l}\text { Mean } \\
\text { square }\end{array}$ & $\mathrm{F}$ & $P$ \\
\hline $\begin{array}{l}\text { Deviation of } \\
\text { group means }\end{array}$ & 192.5 & 6.3 & .01 \\
\hline $\begin{array}{l}\text { Equality of } \\
\text { slopes }\end{array}$ & $1,947.5$ & 78.8 & .19 \\
\hline Error & 24.7 & & \\
\hline
\end{tabular}

\begin{tabular}{lcc}
\hline \multicolumn{3}{c}{ Pairwise comparisons of regression results } \\
\hline Contrast & $\begin{array}{c}P \text { for } \\
\text { means }\end{array}$ & $\begin{array}{c}P \text { for } \\
\text { slopes }\end{array}$ \\
\hline High SES-low SES & $<.01$ & NA \\
High SES-Indian & $<.01$ & NA \\
Low SES-Indian & $<.01$ & NA \\
\hline
\end{tabular}


$T A B L E$ 7. Analysis of covariance for the bone age measurements of girls from each school

\begin{tabular}{|c|c|c|c|}
\hline & \multicolumn{3}{|c|}{ School samples } \\
\hline & High SES & Low SES & Indian \\
\hline $\begin{array}{l}\text { Sample size } \\
\text { Mean } \\
\text { Adjusted mean } \\
\quad \text { (SE) } \\
\text { Constant } \\
\text { Coefficient } \\
\text { SE of regression } \\
\mathrm{R}^{2} \\
\text { Significance } \\
\end{array}$ & $\begin{array}{l}497 \\
8.8 \\
9.3 \\
(.06) \\
-1.2 \\
1.13 \\
1.1 \\
0.87 \\
<0.01 \\
\end{array}$ & $\begin{array}{c}473 \\
8.7 \\
8.4 \\
(.05) \\
-2.6 \\
1.19 \\
1.3 \\
0.77 \\
<0.01 \\
\end{array}$ & $\begin{array}{c}364 \\
8.6 \\
8.3 \\
(.06) \\
-2.2 \\
1.15 \\
1.1 \\
0.79 \\
<0.01 \\
\end{array}$ \\
\hline \multicolumn{4}{|c|}{ Tests of regressions } \\
\hline & $\begin{array}{c}\text { Mean } \\
\text { square }\end{array}$ & F & $\underline{P}$ \\
\hline $\begin{array}{l}\text { Deviation of } \\
\text { group means }\end{array}$ & 1.8 & 1.2 & NS \\
\hline $\begin{array}{l}\text { Equality of } \\
\text { slopes } \\
\text { Error } \\
\end{array}$ & $\begin{array}{l}2.2 \\
1.5 \\
\end{array}$ & 1.5 & NS \\
\hline
\end{tabular}

\begin{tabular}{lcc}
\hline \multicolumn{3}{c}{ Pairwise comparisons of regression results } \\
\hline & $\begin{array}{c}P \text { for } \\
\text { means }\end{array}$ & $\begin{array}{c}P \text { for } \\
\text { slopes }\end{array}$ \\
Contrast & NA & NA \\
High SES-low SES & NA & NA \\
High SES-Indian & NA & NA \\
Low SES-Indian & &
\end{tabular}

eral SES, has less of an effect on the development of bone age than it does on growth in height and weight.

The "Tests of regressions" for the girls (Tables 5-7) show that significant differences exist between the three school groups in amount of growth for height and weight. No overall difference in amount of bone age development was found. The pairwise contrasts for amount of growth in height and weight are significant for all school groups (i.e., high SES Ladino > low SES Ladino > low SES Indian). Pairwise contrasts for rate of growth in height are significant between the high SES Ladino girls and both groups of low SES girls but not between the low SES Ladinos and low SES Indians. Pairwise contrasts were not applicable for amount of bone age development nor for rate of growth in weight and bone age due to the lack of significance of the "Tests of regressions."

The F statistics for each of the "Tests of regressions" for the girls are much smaller than the F statistics for the boys; this is especially noteworthy in the case of the tests that achieve statistical significance. Smaller
$F$ values may indicate that the differences between school groups in social, economic, and ethnic variables influence the growth of the girls less than it influences the boys.

\section{DISCUSSION}

Distances and velocities of growth in height and weight of high SES Ladino children, from the same population represented in the present study (but different individuals), have been analyzed previously (Johnston et al., 1973, 1976; Bogin and MacVean, 1978, 1983). Compared with similarly privileged children living in North America or Europe, wealthy Guatemalan children have somewhat slower rates of growth in height during the preadolescent years but comparable growth rates during adolescence in terms of both age at onset of the adolescent growth spurt and the magnitude of peak growth velocity. In other analyses, it was shown that the high SES Ladinos may serve as the most appropriate reference for the comparison of measures of body composition and the evaluation of nutritional status for all Guatemalan children (Bogin and MacVean, 1981; Johnston et al., 1984). Thus, the pattern of growth and development of the high SES Ladino sample of children may be used as a basis for comparison with the low SES Ladino and very low SES Indian samples.

When dealing with populations that are diverse both socioeconomically and ethnically, such as those considered in this study, it is always difficult to disentangle the environmental and hereditary influences on growth. Differences in language and social customs are effective barriers to marriage, and this leaves open the possibility of genetic determination of the patterns of growth of Ladinos and Indians in Guatemala. However, lacking genetic evidence for differences between the school groups, it is more profitable to interpret the findings in terms of some major environmental determinants of growth, such as quality of diet, health care, and other conditions of life.

Across the range of chronological ages considered in this study, the low SES Ladino and Indian children are smaller in height and weight, and delayed in skeletal maturation, compared with high SES children. The graphic analysis shows that the differences in size are established before the children entered school. Habicht et al. (1974) and 
Van Loon et al. (1986) show that on a worldwide basis, the growth of infants from a variety of ethnic and socioeconomic classes is remarkably similar during the first 6 months of age. After 6 months of age children from higher SES classes and lower SES classes become divergent in size. As a cause for this pattern Habicht, Van Loon, and their colleagues point out that after 6 months of age breast milk can no longer supply sufficient nutrients and antibodies to meet the needs of the infant. Thus, inadequacies in nutrition and health care of the lower SES classes may be predominant causes for their poor growth relative to the high SES classes.

Clearly, the divergence in growth that started during the preschool years continues during the primary-school years. For the boys, the difference in rate of growth between the high and the low SES groups generally increases with age and becomes greatest at the time of the adolescent spurt in height and weight. For the girls, only growth increments in height show an increasing disparity with age between school groups.

Much of the difference in size and maturity between the high and low SES groups has an environmental cause. Dietary and anthropometric surveys in Guatemala and elsewhere in Central America demonstrate consistently that low SES Ladinos and low SES Indians suffer from chronic undernutrition (INCAP, 1969; Martorell et al., 1976; Malina et al., 1980; Bogin and MacVean, 1981). The stress of undernutrition is compounded by increased incidence of infectious disease (Scrimshaw et al., 1968).

Living in Guatemala City, low SES Ladinos face the problems associated with urban poverty, including poor working conditions, wages, and benefits, and inadequate housing in addition to limits on diet and health care. Rural populations face even worse situations. The Indian town of this study has no safe waste-disposal facilities. Samplings of water from the town's water supply show unacceptably high levels of bacterial counts and contamination from fertilizers and pesticides used on agricultural fields around the town (Dr. Jack Schuster, Universidad del Valle, personal communication). These conditions of life are not recent developments. Comparisons of cross-sectional growth data collected in the 1960 s and the 1980s show that Indian children have not experienced any significant change in height and weight during the last 25 years (Bogin and MacVean, 1984).

Comparisons of the F statistics from the ANCOVA indicate that among the three school groups, the growth of the boys is more sensitive to SES and ethnic differences than is the growth of the girls. Stinson (1985) reviewed a wide range of biological phenomena for which boys often show greater environmental sensitivity than do girls. Hypotheses as to the cause of the sex difference include, among others, that girls are more resistant to environmental influences due to 1 ) the presence of two $X$ chromosomes (better genetic buffering against the environment than boys with $X$ and $Y$ chromosomes), 2) the more rapid rate of maturation of girls than boys (hence, less time to respond to environmental stress), or 3) a more restricted social and economic life for girls, leading to fewer opportunities for exposure to various environmental stresses. No definitive explanation, however, is universally accepted.

The ANCOVA results also indicate that SES and ethnic variation between the school groups has less of an effect on skeletal development than it has on growth in height and weight. This is not an unexpected finding: in fact, it has been seen in previous work with Guatemalan urban children (Bogin and MacVean, 1983), Guatemalan rural children (Martorell et al., 1979), and in general reviews of the genetics of skeletal maturation (Bailey and Garn, 1986). In practical terms, the relatively greater delay in growth than in skeletal maturation of the lower SES children means that they are likely to remain significantly shorter and lighter than high SES children at all ages, and remain smaller as adults. Even if living conditions for the children from the low SES groups were to improve, the advancement of bone age relative to size limits the opportunity for "catchup" growth in these children. Better living conditions would, of course, benefit these children, and the implementation of better conditions should be a goal of research workers and policy makers. Indeed, some of the consequences of a pattern of childhood growth that leads to reduced adult size are diminished work capacity and health status (Spurr, 1983; Shephard, 1985) leading to a limited potential for socioeco- 
nomic improvement (Bogin, 1988, pp. 148$159)$, thus recycling low SES and poor growth into future generations.

The findings of this paper add evidence to the scientific literature that public health intervention programs are much needed for children from the low SES classes in Guatemala and, most likely, for those of other developing nations. These programs must start with children at early ages and continue for at least one generation to have optimal benefit. At the very least, safe drinking water and routine pediatric health care need to be provided. To achieve these goals human biologists committed to alleviating the suffering of low SES children and adults need to make the results of their research available to policy makers and to the public.

\section{ACKNOWLEDGMENTS}

Generous support of the American Philosophical Society contributed to this research. Our appreciation to the staff of the Oficina de Investigacion at the Universidad del Valle and to Maureen Wall for assistance in preparation of the data for analysis. Our thanks to two anonymous reviewers whose comments improved the presentation of this paper.

\section{LITERATURE CITED}

Bailey SM, and Garn SM (1986) The genetics of maturation. In F Falkner and JM Tanner (eds.): Human Growth, Vol. 3 (2nd edition). New York: Plenum, pp. 169-195.

Bogin B (1988) Patterns of Human Growth. New York: Cambridge University Press.

Bogin B, and MacVean RB (1978) Growth in height and weight of urban Guatemalan children of low and high socioeconomic class. Hum. Biol. 50:477-487.

Bogin B, and MacVean RB (1981) Body composition and nutritional status of urban Guatemalan children of high and low socioeconomic class. Am. J. Phys. Anthropol. 55:543-551.

Bogin B, and MacVean RB (1983) The relationship of socioeconomic status and sex to body size, skeletal maturation, and cognitive status of Guatemala City school children. Child Dev. 54:115-128.

Bogin B, and MacVean RB (1984) Growth status of nonagrarian, semi-urban living Indians in Guatemala. Hum. Biol. 56:527-538.
Brownlee KA (1965) Statistical Theory and Methodology in Science and Engineering. New York: Wiley.

Fox DJ, and Guire KE (1976) Documentation for MIDAS. Ann Arbor: Statistical Research Laboratory, University of Michigan.

Greulich WW, and Pyle SI (1959) Radiographic Atlas of Skeletal Development the Hand and Wrist. 2nd edition. Stanford, California: Stanford University Press.

Habicht J-P, Yarbrough C, Martorell R, Malina RM, and Klein RE (1974) Height and weight standards for preschool children. Lancet 1:611-615.

Johnston FE, Borden $M$, and MacVean RB (1973) Height, weight and their growth velocities in Guatemalan private school children of high socio-economic class. Hum. Biol. 45:627-641.

Johnston FE, Wanier H, Thissen D, and MacVean RB (1976) Hereditary and environmental determinants of growth in height in a sample of children and youths of Guatemalan and European ancestry. Am. J. Phys. Anthropol. 44:469-476.

Johnston FE, Bogin B, MacVean RB, and Newman BC (1984) A comparison of international standards versus local reference data for the triceps and subscapular skinfolds of Guatemalan children and youth. Hum. Biol. 56:157-171.

INCAP (1969) Evaluacion Nutricional de la Poblacion de Centro America y Panama. Guatemala City: Institute of Nutrition of Central America and Panama.

Malina RM, Selby HA, Buschang PH, and Aronson WL (1980) Growth status of school children in a rural Zapotec community in the Valley of Oaxaca, Mexico, in 1968 and 1978. Ann. Hum. Biol. 7:367-374.

Martorell R, Yarbrough C, Lechtig A, Delgado H, and Klein RE (1976) Upper arm anthropometric indicators of nutritional status. Am. J. Clin. Nutr. 29:46-53.

Martorell R, Yarbrough C, Klein RE, and Lechtig A (1979) Malnutrition, body size, and skeletal maturation: Interrelationships and implications for catch-up growth. Hum. Biol. 51:371-389.

Pettersen CL (1976) Maya of Guatemala: Life and Dress. Guatemala City: Ixchel Textile Museum.

Scrimshaw NS, Guzman MA, Flores M, and Gordon JE (1968) Nutrition and infection field study in Guatemalan villages, 1959-1964. Arch. Environ. Health 16:223-234.

Shephard RJ (1985) Factors associated with population variation in physiological working capacity. Yrbk. Phys. Anthropol. 28:97-122.

Spurr GB (1983) Nutritional status and physical work capacity. Yrbk. Phys. Anthropol. 26:1-35.

Stinson S (1985) Sex differences in environmental sensitivity during growth and development. Yrbk. Phys. Anthropol. 28:123-147.

Van Loon H, Saverys V, Vuylsteke JP, Vlietnck RF, and Eeckels R (1986) Local versus universal growth standards: The effect of using NCHS as a universal reference. Ann. Hum. Biol. 13:347-357.

van't Hoff MA, Roede MJ, and Kowalski CJ (1977) A mixed longitudinal data analysis model. Hum. Biol. 49:165-179. 